\title{
Problems of LSP-Didactics Shown in Case of Specialized Genre of Touristic Websites
}

\author{
Annikki Koskensalo \\ University of Turku, Turku, Finland
}

\begin{abstract}
The purpose of the paper aims at trying to define genre in general and particularly in describing specialized genres like digital genres in case of touristic websites. There are a lot of problems in order to get clear categories and characteristics of the fuzzy subject because of genre-hybridism, individualization, genre-colonization, genre-combination, inter-textuality, multi- and trans-genericity. The topic deals with problems of LSP-didactics shown in case of the specialized genre of touristic websites. The method is inductive, descriptive, and analytical. The empirical transdisciplinary method-mix consists of methods developed by Bhatia (applied genre analysis), Askehave and Nielsen (digital genre analysis), Heyd (two-level analysis model of CMC genres), Herring (web content analysis), Androutsopoulos (language analysis in SNS and CSS), Santini (analysis of genre hybridism and individualization), Marti and Stengel (functional analysis of Web 2.0 applications). The achievement of this article will be a better understanding of digital genres in case of touristic websites within frame conditions like globalization, localization, transculturality, and usability.
\end{abstract}

Keywords: LSP-didactics, digital genres, genre colonization, touristic websites, usability

\section{Introduction}

The concept of genre variability as a consequence of new communicative needs and forms of communication like the Internet is characterized by extremely dynamic processes of recycling, re-contextualization, modifications, and hybridizations. Santini (2007) is characterizing web pages with two aspects: genre hybridism (inter-discursivity in genre theory (Bhatia, 2012, p. 25)) and individualization. Therefore, we have to deal with a large number of emerging genres, with genres still in formation, not fully standardized. Because the web is fluid, unstable, fast-paced and genres on the web are instantiated in web pages, which constitute a complex type of document more composite and unpredictable than paper documents (Santini, 2007, p. 1).

Digital genres have to be brought in relation with phenomena like multi-genericity, inter-textuality, genre colonization (Bhatia, 2002, p. 8), genre combination, and trans-genericity (Villanueva, Ruiz-Madrid, \& Luzon, 2010, p. 9). A lot of case studies have come to the conclusion that digital genre candidates are really hybrid or bridging (Herring, Scheidt, Wright, \& Bonus, 2005). The causality between the high popularity of Swalesian genre theory and therefore the focus on functional understanding of genre has made evident that the technicality of the Internet as a medium provides so many pathways of communication that it may ultimately engender new

Annikki Koskensalo, professor, doctor, Department of Teacher Education, University of Turku. 
purposes/function, and thus new genres (Heyd, 2009, p. 246). A very good example concerning the high dynamicity and variability of specialized genres is touristic websites in relation to past, present, and future. Trying to define genre in general and to describe specialized genres in case of touristic websites shows a lot of problems to get clear categories and characteristics of the subject.

Therefore, genres have to be seen as fuzzy categories, which cannot be defined by necessary and sufficient conditions (Chandler, 1997, p. 3). Usability of touristic websites is the ultimate key for business success. Wordings is a central aspect of usability of touristic websites. Self declaring navigation points, a clear standardized navigation and medium fitting contents are decisive conditions for good usability in future. LSP-didactics can support wordings using transcultural and trans-disciplinary theories and methods.

\section{Definition and Theory of the Concept of Genre}

Genre is defined as the term of any category of literature, wording other forms of art and culture based on a loose set of stylistic criteria. Swales (1990) considered genre as "a class of communicative events, the members of which share some set of communicative purposes” (p. 58). Following more intensively Swales' focus on communicative purposes, Bhatia (1993) observed that "each genre is an instance of a successful achievement of a specific communicative purpose using conventionalized knowledge of linguistic and discoursal resources” (p. 16). Devitt (2004) stated that "culture defines what situations and genres are likely or possible" (p. 24). Genre is further defined by recurring individual's interactions with and within environments. In order to understand better the later presented typology of specialized sub-genres of touristic websites the viewing of genre as an ecosystem will be very helpfully (Barwarshi, 2001, pp. 69-80). Doing this way there is demonstrated how writing creates genres as well as genre recreates writing. Genre itself serves as an ecosystem, defining interpretation and creation of genre.

A genre can be recognized based on the characteristics, which a situation offers. Devitt (2004, p. 10) argued that a genre is named because of its formal markers. This demonstrates how reciprocity functions within genre. Relating genre with context theoretically as well as practically is essentially important. Genre understood in terms of social contexts provides a greater meaning to each recurring situation. It makes differentiation possible because past genres play a role in present and new genres. Therefore, genre is aimed to continue evolving like social contexts continue to change with time. Barwarshi (2001) described how it happens: "communicants and their social environments are constantly in the process of reproducing one another.... We create our contexts as we create our texts” (p. 69). A very important theoretical aspect figures genre as a social action, which provides the "keys to understanding how to participate in the actions of a community" (Miller, 1984, p. 165). Genre is also determined based “on the action it is used to accomplish” (Miller, 1984, p. 165). Fairclough (2003) described the role of genres in relation to the social context of a text that genres are "different ways of (inter)acting discourse” (p. 26).

In summary, genre is defined by different categories, styles, media, epochs, and conventions. Genres are specified and determined by subgenres. The concept of genre is closely connected with other important concepts like ecosystem, context, and social action. Vazquez y del Arbol (2005) considered also in a very holistic way the complex meaning of genre "as a formal discourse category, either oral or written, which shares some characteristics, such as the area it belongs to, readership of the text, author, macrostructure, content and 
communicative purpose” (p. 147). Santini (2012, p. 1) defined very similarly genre like Charaudeau, Maingueneau, and Adam (2002) genre as "class of texts with similar communicative, textual and linguistic features” (p. 278). A genre must have a name, be recognized within a community, produced or retrieved during a task, have conventions, raise expectations, and can change over time. A genre is a cultural artifact, where culture includes society, media, technology, etc. (Santini, 2012, p. 1). An inclusive theory of genre should address the following interrelated dimensions: (1) the purpose intended by the producer; (2) textuality features like hypertextuality, interactivity, interdiscursivity, multimodality, and textual regularities; and (3) patterns of usage in the form of questions like: (a) How do particular users interact with the document? (b) What is its function in a social context? (c) How users combine genres to accomplish social actions? (d) Who combines genres, when, where, and for what purpose? (Villanueva et al., 2010, p. 10).

\section{A Typology of Specialized Sub-genres of Touristic Websites}

Digital genres are any kinds of genre which have a digital form, such as emails, chats, online academic papers, online newspapers articles, and blogs. They can be any paper genres converted into a digital form or classes of texts which do not have any counterpart in the paper world, such as home pages, about us web pages, Frequent Asked Questions (FAQs), webzine articles, personal blogs, and corporate weblogs (Santini, 2012, p. 1). Digital genres act in a two-dimensional view as a text and also as a medium (Askehave \& Nielsen, 2005a, p. 120) which have characteristics of non-linear, multi-modal, and web-mediated documents (Askehave \& Nielsen, 2005b, p. 1). Digital genres are highly dynamic forms often characterized by hybridism (Villanueva et al., 2010, p. 8). Because of the multimodal nature of digital genres a large number of researches have called for a semiotic theory of genre leaving behind the linguistic paradigm, which can then account equally well for color, 3D object, gesture, image, music, speech, writing, etc.. Websites and mobile technologies are technologies serving the Internet (Gretzel, 2009, p. 152). There has to be considered that the web is a very complex scenario where the mixture of several genres in a single web page is a fast operation, where the lack of any institutionalized control can stimulate authorial creativity and individualization and where the constant introduction of web technologies brings about the transitional phase of emerging genres with unclear genre conventions (Santini, 2007, p. 8).

In order to understand better the specialized genre of touristic websites there should be used a framework for analysis and description: (1) a heuristic description based upon a semiotic and content analysis allowing to determine the combination of semiotic cues used by the reader to interact with and throughout the text and to construct meaning; (2) an analysis of the structure and design of the website (architecture, the way how different pages in a website are linked together and connected; and (3) an analysis of the hyper-textuality and multi-genericity of the website, which is very useful to determine how users are constructing meaning by traversing genres and sites (Villanueva et al., 2010, p. 9). Charaudeau, Maingueneau, and Adam (2002, p. 278) differentiated between four different analytic conceptualizations of genre: (1) linguistic function, (2) formal traits, (3) textual organization, and (4) relation of the communicative situation to formal and organizational traits of the text. These four conceptualizations have to be brought into relation with the typology of main-, sub-genres, and Web 2.0-applications (Stengel, 2010, pp. 233, 226; Marti, 2002, p. 140) (see Table 1 in the Appendix). In this model of Stengel and Marti, there are four main-functions: (1) information, (2) aggregation, 
(3) matching, and (4) confidence building. In order to show the empirical conditions of our main topic and according to these main-functions there are sub-functions implemented by different Web 2.0-applications, which also can be supported by other applications like Mashup, Tagging, and Geolocation: Information includes providing of travelling informations, search and evaluation and analyzing customer's preferences. Serving Web 2.0-applications are rating portals (Holidaycheck, Tripadvisor), travelling-communities (Trips by Tips, Lonley Planet Thorn Tree, GEO), social networks (Couchserving for search and evaluation), video- and photo-platforms (Travelistic, Youtube, Flickr), and Wikis (Wikitravel, Wikivoyage, World66). Information figures as the biggest area of service especially when planning and preparing a trip or journey. Aggregation includes reduction of asymmetries and creation and clustering of sortiments. Serving Web 2.0-applications are also rating portals, communities (Trip by Tips, Lonley Planet Thorn Tree, Tripwolf), and Wikis (Wikitravel, Wikivoyage, World66). Creation and clustering of sortiments are supported by rating portals like Holidaycheck, Tripadvisor, and Trustyou. Matching helps to find individual customer's preferences fitting optimal offer. Matching means to search the most interested travelling-target-group according to the optimal touristic supply, Web 2.0-applications like blogs (TravelBlog, Travelpod), communities (Trips by Tips, Lonely Planet Thorn Tree, Tripwolf), and social networks (CouchSurfing). Possibilities of the sematic web will decisively improve the counseling-service in future (Stengel, 2010, p. 234). Confidence building will be realized by risk reduction and quality evaluation. Serving Web 2.0-applications are rating portals like Holidaycheck and Tripadvisor and communities like Trips by Tips, Lonely Planet Thorn Tree, and Tripwolf. Risk reduction also will be reached by video- and photo-portals like Travelistic, Youtube, and Flickr. All these Web 2.0-applications represent during the production of collective knowledge an almost neutral, objective, and believable information and are surely depending of criteria like independence, authenticity, plurality, and actuality (Rengelshausen \& Schmeißer, 2007).

The specialized genre of touristic websites has to be more precisely defined as a changing mosaic or combination of sub-genres created by rating portals (websites or online portals, where user can communicate their last made experiences of travelling), communities, social networks (private or professional networks), video- and photo-platforms (sometimes RSS-Feed added), Wikis (websites, where users can install, read, and alter texts), and Blogs (e.g., travel diaries). The concept of high dynamic and variation of specialized genres like touristic websites will become more complicated if it will be combined with four dimensions of language in social networking sites (SNS) and content sharing sites (CSS) (Androutsopoulos, 2010, p. 211). Androutsopoulos 2010, p. 211) combines in his model (see Table 2 in the Appendix) four dimensions like organization, self-representation, spectacle, and interaction with agency. Organizations are creating web interfaces as part of web design with the agency of a site designer with typical sites (SNS and CSS). Self-presentation deals the resource for profile pages and other sites of user presentation with the agency of the individual user and typical site of SNS. Spectacle represents a part of multimedia material people upload and make available with the agency of user and the typical site of CSS (and embedded in SNS). Interaction deals with means for interpersonal communication and comments on "prompts" with the agency of being multi-authored and the typical site of SNS and CSS. Androutsopoulos (2010, p. 211) suggested that spectacles are central to the current stage of digital discourse. He also argued that the co-existence of and the interplay between the four dimensions of language characterizes contemporary web environments. All four 
dimensions are practically and constantly inter-related. Therefore, it is useful to think of processes of globalization and localization as involving in principle all four dimensions. Esselink (2000) offered the following definition of globalization:

Globalization adresses the business issues associated with taking a product (or service A.K.) global. In the globalization of high tech products (services A.K.) this involves integrating localization throughout a company, after proper internationalization and product (service A.K.) design, as well as marketing, sales and support in the world market. (p. 4)

The topic handled before is very closely connected with the concept of internationalization, which is "the process of generalizing a product (or service A.K.), so that it can handle multiple languages and cultural conventions without the need for re-design. Internationalization takes place at the level of program design and document development” (Esselink, 2000, p. 25). So there should be in consequence no tables in the text, no fixed formats of data or measurement parameters, or country specific icons and symbols. There should also be consequently a division between codes of program and text. Localization represents a "process of modifying a website for a specific locale” (Yunker, 2002, p. 17). Localization of (touristic) websites deals with not only with simple translating but with transfer of the complete contents of language and culture to the target group including also tables, soundpads, other multi-media-components, and in case of dynamic websites (like touristic websites A.K.) data-bank-connections (Gander, 2005, p. 3). Tendencies of globalization have effects concerning the global, supranational, European, and local communication behavior of human individuals producing phenomena in each language as an important actor and mediator of culture. The main question of research has to be asked: Which influence have verbal and nonverbal global communication codes in writing text-communicative behavior of internet users shown for example at advertisement language of touristic websites under conditions like social networking, e.g., weblog networks, blogs, RSS-Feeds, and Tweets? Another question will be: How influences globalization as individualism on the level of advertisement language used by human beings in each of their life situations? Answers to all of these questions will help for a better understanding the nature of specialized genres of touristic websites. A lot of research has to be done in future. On the other hand no touristic website will have a chance to survive without standards like a clearly standardized navigation, clear visual design, and clearly communicated value of brand (Zerfaß \& Zimmermann, 2004, p. 11). Therefore, wordings figures as a central aspect of usability of (touristic) websites. It should be secured that the choosing of words has to be intuitively understandable concerning the most important points of navigation (Wöhrmann, 2004, p. 22). Concerning wording there should be developed a lexicon of LSP with special focus to the field of touristic communication, which should be able to declare special terminology in simple words to every user. Practically there should be a meeting of tourism experts, experts in the field of communication, marketing, computer sciences, and LSP-didactics in order to develop and install such a lexicon. Empirical studies have proved that there are cultural differences in online-searching behavior (Lee, Soutar, \& Daly, 2008, pp. 165-176). In such specific conditions LSP-didactics has to achieve transcultural competence under conditions of transcultural and trans-disciplinary assumptions and the assumption of a linguistic-contrastive point of viewing. Trans-culture has to be defined as a concept of culture in an open instable process where meanings will be negotiated. In this cognitive process competent actors will be connected as equal partners negotiating different topics aiming at a compromise of identified restrictions of interests. Trans-disciplinarity 
will be used, if tasks of research have to be realized by research teams unified as a task force and the borders of the respective own discipline have to be crossed. The aim will be: Optimized communication is more understandable, instructive, and persuasive (Strohner, 2002, p. 81).

\section{Summary}

The principle of change between different forms of symbolization each together with an own function and language of symbols offers also in the case of touristic websites a big didactical range of possibilities in order to understand better the dynamicity and variability of this type of specialized genres (see Figure 1 in the Appendix). LSP-didactics can support the standardizing and localizing of specialized genre "touristic websites".

\section{References}

Androutsopoulos, J. (2010). Localizing the global on the participatory web. In N. Coupland (Ed.), The handbook of language and globalization (pp. 203-231). Malden, MA: Wiley.

Askehave, I., \& Nielsen, A. E. (2005a). Digital genres: A challenge to traditional genre theory. Information, Technology \& People, 18(2), 120-141.

Askehave, I., \& Nielsen, A. E. (2005b). What are the characteristics of digital genres? Proceedings of the 38th Hawaii International $\begin{array}{llll}\text { Conference } & \text { System } & \text { Sciences. } & \text { Retrieved }\end{array}$ http://files.ynada.com/archive/Askehave\%20and\%20Nielsen\%20-\%20Characteristics\%20of\%20Digital\%20Genres.pdf

Barwarshi, A. (2001). The ecology of genre. In C. R. Weisser \& S. I. Dobrin (Eds.), Ecocomposition: Theoretical and pedagogical approaches (pp. 69-80). Albany: SUNY Press.

Bhatia, V. (1993). Analysing genre. London: Longman.

Bhatia, V. (2002). Applied genre analysis: A multi-perspective model. Iberica, 4, 3-19.

Bhatia, V. (2012). Critical reflections on genre analysis. Iberica, 24, 17-28.

Chandler, D. (1997). An introduction to genre theory. Retrieved from http://www.aber.ac.uk/ mcswww/Documents/intgenre/intgenre.html

Charaudeau, P., Maingueneau, D., \& Adam, J. -M. (2002). Dictionaire d' analyse du discours (Dictionary discourse analysis). Paris: Seuil.

Devitt, A. J. (2004). A theory of genre. Writing genres. Carbondale: Southern Illinois UP.

Esselink, B. (2000). A practical guide to localization. Amsterdam: Benjamins.

Fairclough, N. (2003). Analysing discourse. London: Routledge.

Gander, A. (2005). Herausforderung Website-Lokalisierung (The challenge of website-localization). infotrend, 3.

Gretzel, U. (2009). Das Online-Suchverhalten von Touristen (Online-search behavior of tourists). Zeitschrift für Tourismuswissenschaft, 2(1), 151-164.

Herring, S. (2010). Web content analysis. In J. Hunsinger, M. Allen, \& L. Klastrup (Eds.), The international handbook of Internet research (pp. 233-249). Dordrecht: Springer.

Herring, S., Scheidt, L., Wright, E., \& Bonus, S. (2005). Weblogs as a bridging genre. Information, Technology \& People, 18(2), $142-171$.

Heyd, T. (2009). A model for describing “new” and “old” properties of CMC genres. In J. Giltrow \& D. Stein (Eds.), Genres in the internet: Issues in the theory of genre (pp. 239-262). Amsterdam: Benjamins.

Lee, J., Soutar, G., \& Daly, T. (2007). Tourist's search for different types of information: A crossnational study. Journal of Information Technology \& Tourism, 9(3\&4), 165-176.

Marti, E. (2002). Electronic commerce im Reisemarkt. Lohmar/Köln: Eul.

Miller, C. (1984). Genre as social action. Quarterly Journal of Speech, 70, 151-167.

Rengelshausen, O., \& Schmeißer, D. R. (2007). Touristik 2.0: Chancen und Risiken von User Generated Content für den Online-Reisevertrieb (Touristic 2.0: Opportunities and risks of user generated content of online-travel-distrribution). Planung \& analyse, 4, 2-5.

Santini, M. (2007). Characterizing genres of web pages: Genre hybridism and individualization. Proceedings of the 40th Hawaii International Conference on $\quad$ System $\quad$ Sciences. http://ieeexplore.ieee.org/stamp/stamp.jsp?tp=\&arnumber=4076514

Santini, M. (2012). Towards a computational theory of digital genre (I). Retrieved from 
http://www.forum.santini.se/category/dialectic/

Stengel, N. (2010). Online-Offline. Reiseberatung 2.0-Vom Reisebüro zum Web 2.0 (Online-offline. Travel-service 2.0—From travel-office to Web 2.0). In R. Egger \& T. Herdin (Eds.), Tourismus im Spannungsfeld von Polaritäten (Tourism in the critical field of polarities) (Vol. 2, pp. 223-235). Wien/Berlin: LIT (Wissenschaftl. Schriftenreihe der FHS-Forschungsgesellschaft).

Strohner, H. (2002). Methoden der Kommunikationsoptimierung (Methods of improving communication). In H. Strohner \& R. Brose (Eds.), Kommunikationsoptimierung (Improvement of communication) (Vol. 30, pp. 81-90). Tübingen: Stauffenburg Linguistik.

Swales, J. (1990). Genre analysis. Cambridge: CUP.

Vazquez y del Arbol, E. (2005). A genre-based study of biomedical editorials and letters of the editor: A contrastive analysis. Iberica, 10, 145-160.

Villanueva, M. L., Ruiz-Madrid, M. N., \& Luzon, M. J. (2010). Learner autonomy in digital environments: Conceptual framework. In M. J. Luzon, M. N. Ruiz-Madrid, \& M. L. Villanueva (Eds.), Digital genres, new literacies and autonomy in language learning (pp. 1-23). Newcastle upon Tyne: Cambridge Scholars Publishing.

Wöhrmann, M. (2004). Wording als zentraler Aspekt der Usability von Websites (Wording as a main aspect of usability of websites). In A. Zerfaß \& H. Zimmermann (Eds.), Usability von Internet-Angeboten: Grundlagen und Fallstudien (Usability of internet-offers: Basics and case-studies) (Vol. 10, pp. 21-23). Stuttgart: Stuttgarter Beiträge zur Medienwirtschaft.

Yunker, J. (2002). Beyond borders. Web globalization strategies. Indianapolis: New Riders.

Zerfaß, A., \& Zimmermann, H. (Eds.). (2004). Usability von Internet-Angeboten. Grundlagen und Fallstudien (Usability of internet-offers: Basics and case-studies) (Vol. 10, pp. 1-38). Stuttgart: Medien- und Filmgesellschaft Baden-Württemberg (Stuttgarter Beiträge zur Medienwirtschaft).

\section{Appendix: Tables and the Figure Mentioned in the Paper}

Table 1

Main-, Sub-functions and Web 2.0-Applications

\begin{tabular}{|l|l|l|}
\hline Function & Sub-fuction & Web 2.0-applications \\
\hline Information & $\begin{array}{l}\text { providing of travelling information } \\
\text { search and evaluation } \\
\text { analysing customer's preferences }\end{array}$ & $\begin{array}{l}\text { rating portals } \\
\text { communities } \\
\text { social networks } \\
\text { video- and photo-platforms } \\
\text { Wiki }\end{array}$ \\
\hline Aggregation & $\begin{array}{l}\text { reduction of asymmetries } \\
\text { creation and clustering of sortiments }\end{array}$ & $\begin{array}{l}\text { rating portals } \\
\text { communities } \\
\text { video- and photo-platforms }\end{array}$ \\
\hline Matching & search of individual customer's preferences & $\begin{array}{l}\text { blogs } \\
\text { communities } \\
\text { social networks }\end{array}$ \\
\hline Confidence building & $\begin{array}{l}\text { confidence building } \\
\text { risk reduction }\end{array}$ & $\begin{array}{l}\text { rating portals } \\
\text { communities } \\
\text { video- and photo-platforms }\end{array}$ \\
\hline
\end{tabular}

Note. Source: Adapted from (Stengel, 2010, p. 233; Marti, 2002, p. 140).

Table 2

Four Dimensions of Language in Social Networking Sites (SNS) and Content Sharing Sites (CSS)

\begin{tabular}{|l|l|l|l|}
\hline Dimension & Main characteristic & Agency & Typical site \\
\hline Oranization & Constitutes web interfaces as part of web design & Site designer & SNS and CSS \\
\hline Self-presentation & Resouce for profile pages and other sites of user presentation & Individual user & SNS \\
\hline Spectacle & Part of multimedia material people upload and make available & User & $\begin{array}{l}\text { CSS (and embedded in } \\
\text { SNS) }\end{array}$ \\
\hline Interaction & $\begin{array}{l}\text { Means for interpersonal communication and comments on } \\
\text { "prompts" }\end{array}$ & Multi-authored & SNS and CSS \\
\hline
\end{tabular}

Note. Source: Adapted from (Androutsopoulos, 2010, p. 211). 


\section{Typology of Genre}

\section{Genre}

Specialized Genre Touristic Websites (hybrid genre)

Sub- Genres rating portals

communities

social networks

video- and photo- plattforms

wikis

blogs

Source: Annikki Kosensalo

Figure 1. Typology of genre. 